\title{
The causes of prescribing errors in English general practices:
}

\author{
a qualitative study
}

\begin{abstract}
Background

Few detailed studies exist of the underlying causes of prescribing errors in the UK.

Aim

To examine the causes of prescribing and monitoring errors in general practice and provide recommendations for how they may be overcome.

\section{Design and setting}

Qualitative interview and focus group study with purposive sampling of English general practices

\section{Method}

General practice staff from 15 general practices across three PCTs in England participated in a combination of semistructured interviews $(n=34)$ and six focus groups $(n=46)$. Thematic analysis informed by Reason's Accident Causation Model was used.

Results

Seven categories of high-level error-producing conditions were identified: the prescriber, the patient, the team, the working environment, the task, the computer system, and the primary-secondary care interface. These were broken down to reveal various error-producing conditions: the prescriber's therapeutic training, drug knowledge and experience, knowledge of the patient, perception of risk and their physical and emotional health; the patient's characteristics and the complexity of the individual clinical case: the importance

\section{INTRODUCTION}

Prescribing is an essential task for any doctor. It involves weighing up the benefits of treatments against the risk of possible harm. Over 900 million items are dispensed in the community in England each year, ${ }^{1}$ yet relatively little is known about the prevalence and underlying causes of prescribing errors in general practice. ${ }^{2}$ One study explored the causes of preventable, drug-related, admissions to hospital and found problems at multiple stages in the medication use process, including prescribing. ${ }^{3}$ The EQUIP study investigated the causes of prescribing errors by foundation trainees in secondary care and uncovered many factors that led to errors. ${ }^{4}$ The study team also conducted a major study of the causes of prescribing errors in an English hospital, and identified many risk factors including inadequate training and an absence of self-awareness of errors. ${ }^{5}$ A systematic review in 2009 concerning the causes of prescribing errors in specialist and nonspecialist hospitals also reported high workload and inadequate communication between healthcare professionals as errorprovoking conditions. ${ }^{6}$

UK primary care has received relatively
\end{abstract} of feeling comfortable within the practice team was highlighted, as well as the safety implications of GPs signing prescriptions generated by nurses when they had not seen the patient for themselves; the working environment with its extensive workload, time pressures, and interruptions; and computerrelated issues associated with mis-selecting drugs from electronic pick-lists and overriding alerts were all highlighted as possible causes of prescribing errors and were often interconnected.

\section{Conclusion}

Complex underlying causes of prescribing and monitoring errors in general practices were highlighted, several of which are amenable to intervention.

\section{Keywords}

general practice; medication safety; patient safety; prescribing; primary care; quality.
SP Slight, MPharm, PhD, PGDip, senior lecturer Pharmacy and Health, Durham University, Stockton on Tees. R Howard, BPharmHon, PhD, MRPharmS, DipClinPharm, lecturer in pharmacy practice, School of Pharmacy, University of Reading, Reading. M Ghaleb, senior lecturer in patient safety, Department of Pharmacy, University of Hertfordshire, Hatfield. N Barber, FRPharmS, professor of the practice of pharmacy, Centre for Medication Safety and Service Quality, Department of Practice and Policy, UCL School of Pharmacy, London. B Dean Franklin, MSc, PhD, MRPharmS, director and professor of medication safety, Centre for Medication Safety and Service Quality, Department of Practice and Policy, UCL School of Pharmacy and Pharmacy Department, Imperial College Healthcare NHS Trust, Charing in pharmacy practice, School of Medicine little attention. A national reporting and learning service, established to collect spontaneously reported accounts of health-related error, received very little data from primary care organisations. ${ }^{7}$ In the absence of evidence, the aim of this study was to explore the causes of prescribing and monitoring errors, and provide key recommendations for how they may be overcome. This article presents the qualitative findings from the largest, mixed methods study conducted over 2 years in a broad range of general practices in England. 8.9

\section{METHOD}

Ninety-seven practices across three primary care trusts (PCTs; the UK primary healthcare organisations in place at the time of the study) with differing characteristics (inner-city London, urban and suburban, and/or rurall were sent a letter and information sheet inviting them to take part; 30 practices replied with 20 expressing an interest in participating. Of these, five practices in each of the PCTs were purposively selected taking into account differences in demographic characteristics. Pharmacists reviewed a $2 \%$ random sample

Cross Hospital, London. AJ Avery, DM, FRCGP professor of primary health care, Division of Primary Care, The University of Nottingham, Nottingham.

\section{Address for correspondence}

Sarah Patricia Slight, School of Medicine, Pharmacy and Health, Wolfson Research Institute, Durham University, Queen's Campus, University Boulevard, Thornaby, Stockton-on-Tees, TS17 6BH. E-mail: s.p.slight@durham.ac.uk

Submitted: 15 April 2013; Editor's response: 16 April 2013; final acceptance: 18 June 2013. (B) British Journal of General Practice

This is the full-length article (published online 30 Sep 2013) of an abridged version published in print. Cite this article as: Br J Gen Pract 2013. DOI: 10.3399/bjgp13X673739 


\section{How this fits in}

There have been very few detailed investigations of the underlying causes of prescribing errors in the UK. Those studies which already exist have largely been confined to secondary care. This study highlighted a multitude of factors that were found to have contributed to prescribing and monitoring errors in general practice. The prescriber's therapeutic training, drug knowledge and experience were all identified as possible causes, as too were the patient's characteristics and the complexity of the individual clinical case. The working environment, with its high workload, time pressures, and interruptions, was also considered a possible cause. Several of these identified causes are amenable to intervention, including improved training, and more effective clinical governance, while others such as workload, time pressures and interruptions, are likely to be more difficult to address.

of medical records in each practice to identify potential prescribing and monitoring errors. Five members of the research team then decided whether these fitted pre-specified definitions for prescribing and monitoring errors (Box 1). ${ }^{10-12}$

A wide range of different types of errors were purposefully selected, including those that were considered particularly serious, a range of different types of potential prescribing and monitoring errors, potential errors involving problems at the primary-secondary care interface, and less serious problems, where GPs may have wished to debate whether or not an error had taken place. Letters were distributed to prescribers potentially responsible for these errors inviting them to participate in a face-to-face semi-structured interview. A range of members of general practice staff were also invited to attend one of six focus groups, the purpose of which was to discuss safeguards in general

\section{Box 1. Definitions of prescribing and monitoring errors}

A prescribing error occurs when, as a result of a prescribing decision or prescription-writing process, there is an unintentional, significant reduction in the probability of treatment being timely and effective, or increase in the risk of harm when compared to generally accepted practice. ${ }^{10}$

A monitoring error occurs when a prescribed medicine is not monitored in the way which would be considered acceptable in routine general practice. It includes the absence of tests being carried out at the required frequency, with tolerance of $+50 \%$. If a patient refused to give consent for a test, then this would not constitute an error. ${ }^{12}$ practice. The research pharmacists who collected data on potential medication errors were all given training in conducting these interviews. All participants received an information sheet and provided written informed consent.

Face-to-face, semi-structured interviews were conducted between October 2010 and May 2011, audiorecorded with permission and transcribed verbatim; field notes were taken for those who did not wish to be recorded. Any information that could lead to a participant being identified was removed at the transcription stage and an identification code applied (Table 1). Six focus groups were conducted, each with a mix of staff groups (Table 2). One member of the research team led the discussions while another kept note of the contributions made by each participant so as to assist with transcription. All transcribed interviews and focus groups were re-checked for accuracy by a research administrator.

Analysis took place concurrently with data collection, with further refinement of the open-ended questions in the topic guides to investigate areas in more depth. Two authors then generated the conceptual framework ${ }^{13}$ by which these data were labelled and sorted. This process involved identifying recurring themes and concepts in the interviews and focus group transcripts, and was informed by Reason's Accident Causation Model. ${ }^{14} \mathrm{~A}$ list of mainand sub-themes was applied systematically to the whole data set with the aid of the computerised software QSR N-Vivo lversion 8.0). Field notes were also coded and analysed. Using the 'constant comparison' technique, ${ }^{15}$ the lead researcher moved backwards and forwards between these data and evolving explanations until a fit was clearly made. Apparent negative cases' were also examined to further refine the explanations presented.

\section{RESULTS}

A total of 34 participants were interviewed about 70 errors (Table 1), with 32 agreeing to be audiorecorded. Forty-six individuals participated in the six focus groups (Table 2). Seven high-level categories were identified: the prescriber, the patient, the team, the work environment, the task, the computer system, and the primary-secondary care interface. Each of these categories are discussed below, before drawing on their implications.

\section{The prescriber}

Five error-producing conditions were found to affect the prescriber, namely 
Table 1. Characteristics of the interview participants

\begin{tabular}{|c|c|c|c|c|c|c|c|c|c|}
\hline $\begin{array}{l}\text { Participant } \\
\text { identification } \\
\text { labela }^{\text {a }}\end{array}$ & $\begin{array}{l}\text { Length of } \\
\text { audiorecording, } \\
\text { minutes }\end{array}$ & Sex & $\begin{array}{l}\text { Medical } \\
\text { school }\end{array}$ & $\begin{array}{l}\text { Decade } \\
\text { qualified }^{\mathrm{b}}\end{array}$ & $\begin{array}{l}\text { Clinical } \\
\text { interests/ } \\
\text { specialty }\end{array}$ & $\begin{array}{l}\text { Number of } \\
\text { years in } \\
\text { professionc }\end{array}$ & $\begin{array}{c}\text { Role } \\
\text { within } \\
\text { practice }\end{array}$ & $\begin{array}{l}\text { Working } \\
\text { hours }\end{array}$ & $\begin{array}{c}\text { Number of } \\
\text { potential errors } \\
\text { discussed }\end{array}$ \\
\hline PR1-GP1 & 68.0 & $M$ & London & $1980 \mathrm{~s}$ & Prescribing advisor & $15-19$ & GP partner & $\mathrm{F} / \mathrm{T}$ & 4 \\
\hline PR1-GP2 & 36.0 & M & Leicester & $2000 s$ & Men's health, dermatology & $<5$ & GP partner & $\mathrm{F} / \mathrm{T}$ & 1 \\
\hline PR2-GP1d & 21.0 & $F$ & Nottingham & $1980 \mathrm{~s}$ & Gynaecology, depression & $25-29$ & GP partner & $\mathrm{P} / \mathrm{T}$ & 1 \\
\hline PR2-GP2 & 31.3 & $\mathrm{~F}$ & Nottingham & $2000 \mathrm{~s}$ & Women's health and children & $5-9$ & GP partner & $\mathrm{P} / \mathrm{T}$ & 2 \\
\hline PR2-GP3 ${ }^{d}$ & 39.4 & M & Nottingham & 1970s & Minor surgery/injections & $20-24$ & GP partner & $\mathrm{F} / \mathrm{T}$ & 3 \\
\hline PR3-GP1 ${ }^{d}$ & 41.2 & M & Nottingham & $1980 \mathrm{~s}$ & Psychiatry/ENT & $20-24$ & GP partner & $\mathrm{F} / \mathrm{T}$ & 2 \\
\hline PR3-GP2 ${ }^{d}$ & 30.4 & $\mathrm{~F}$ & Nottingham & $1980 \mathrm{~s}$ & Gynaecology & $25-29$ & GP partner & $\mathrm{P} / \mathrm{T}$ & 2 \\
\hline PR4-GP1 & 46.4 & M & Nottingham & $1990 \mathrm{~s}$ & None & $10-14$ & GP partner & $\mathrm{P} / \mathrm{T}$ & 2 \\
\hline PR4-GP2 & 45.5 & $\mathrm{~F}$ & London & $1990 \mathrm{~s}$ & $\begin{array}{c}\text { Palliative care, } \\
\text { contraception, diabetes }\end{array}$ & $10-14$ & GP partner & $\mathrm{P} / \mathrm{T}$ & 3 \\
\hline PR5-GP1 & 19.5 & F & London & $1980 \mathrm{~s}$ & $\begin{array}{l}\text { Women's health and } \\
\text { children, sexual, mental }\end{array}$ & $20-24$ & GP partner & $\mathrm{P} / \mathrm{T}$ & 2 \\
\hline PR5-GP2 & 29.3 & M & London & $1980 \mathrm{~s}$ & Alcohol, mental health & $20-24$ & Senior GP partner & $\mathrm{F} / \mathrm{T}$ & 2 \\
\hline PR5-GP3 & 22.3 & $\mathrm{~F}$ & Sheffield & $1980 \mathrm{~s}$ & None volunteered & $10-14$ & Salaried GP & $\mathrm{P} / \mathrm{T}$ & 1 \\
\hline PR5-GP4 & 25.6 & M & Nottingham & $1980 \mathrm{~s}$ & None volunteered & $15-19$ & GP partner & $\mathrm{P} / \mathrm{T}$ & 0 \\
\hline PR6-GP1 & 34.5 & $\mathrm{~F}$ & Edinburgh & $2000 s$ & Gynaecology, dermatology & $<5$ & GP partner & $\mathrm{P} / \mathrm{T}$ & 3 \\
\hline PR6-GP2 & 29.4 & $\mathrm{~F}$ & Sri Lanka & $2000 s$ & Gynaecology & $5-9$ & GP partner & $\mathrm{F} / \mathrm{T}$ & 2 \\
\hline PR6-NU1 & 12.3 & $\mathrm{~F}$ & Luton & 1990s & None recorded & $10-14$ & Nurse prescriber & $\mathrm{F} / \mathrm{T}$ & 1 \\
\hline PR6-GP4 & 10.1 & $\mathrm{~F}$ & London & $1980 \mathrm{~s}$ & Paediatrics, diabetes & $10-14$ & GP partner & $\mathrm{F} / \mathrm{T}$ & 1 \\
\hline PR7-GP1 & 26.6 & M & Newcastle & $1980 \mathrm{~s}$ & Skin surgery & $15-19$ & GP partner & $\mathrm{P} / \mathrm{T}$ & 1 \\
\hline PR7-GP2 & 7.3 & M & Newcastle & $1980 \mathrm{~s}$ & $\begin{array}{l}\text { Sports medicine, ENT, } \\
\text { diabetes, orthopaedics }\end{array}$ & $15-19$ & GP partner & $\mathrm{F} / \mathrm{T}$ & 1 \\
\hline PR7-GP3 & 27.3 & M & Glasgow & $1970 \mathrm{~s}$ & Chronic diseases & $20-24$ & Senior GP partner & $\mathrm{F} / \mathrm{T}$ & 2 \\
\hline PR7-GP4 & 45.3 & $\mathrm{~F}$ & Newcastle & $1980 \mathrm{~s}$ & Medicines management & $20-24$ & GP partner & $\mathrm{P} / \mathrm{T}$ & 5 \\
\hline PR8-GP1 & 26.0 & M & Liverpool & $1980 \mathrm{~s}$ & Gynaecology & $25-29$ & Senior GP partner & $\mathrm{F} / \mathrm{T}$ & 2 \\
\hline PR9-GP1 & 22.3 & F & Leeds & $1980 \mathrm{~s}$ & Gynaecology & $25-29$ & Senior GP partner & $\mathrm{F} / \mathrm{T}$ & 5 \\
\hline PR10-GP1 & 19.5 & M & Italy & $1990 \mathrm{~s}$ & Asthma, COPD, diabetes & $20-24$ & $\begin{array}{l}\text { Senior GP partner, } \\
\text { clinical lead }\end{array}$ & $\mathrm{F} / \mathrm{T}$ & 3 \\
\hline PR10-GP2 & 16.1 & M & India & $1970 \mathrm{~s}$ & None volunteered & $30-34$ & Senior GP partner & $\mathrm{F} / \mathrm{T}$ & 1 \\
\hline PR11-GP1 & N/A & M & London & $1970 \mathrm{~s}$ & None volunteered & $25-29$ & Senior GP partner & $\mathrm{F} / \mathrm{T}$ & 1 \\
\hline PR11-GP2 & $\mathrm{N} / \mathrm{A}$ & $\mathrm{F}$ & Cambridge & $1980 s$ & Women's health and children & $20-24$ & Senior GP partner & $\mathrm{F} / \mathrm{T}$ & 1 \\
\hline PR12-GP1 & 10.3 & M & Australia & $2000 \mathrm{~s}$ & None & $<5$ & GP partner & $\mathrm{F} / \mathrm{T}$ & 1 \\
\hline PR12-GP2 & 12.5 & M & London & $1980 \mathrm{~s}$ & None & $25-29$ & GP partner & $\mathrm{F} / \mathrm{T}$ & 4 \\
\hline PR13-GP1 & 13.5 & M & Cambridge & $1970 \mathrm{~s}$ & $\begin{array}{l}\text { Gastroenterology, } \\
\text { musculoskeletal }\end{array}$ & $25-29$ & Senior GP partner & $F / T$ & 2 \\
\hline PR13-GP2 & 13.3 & M & Italy & $1970 \mathrm{~s}$ & Paediatrics & $20-24$ & GP partner & $\mathrm{F} / \mathrm{T}$ & 3 \\
\hline PR14-GP1 & 14.6 & M & Sheffield & $2000 s$ & Diabetes, dermatology & $<5$ & Salaried GP & $\mathrm{P} / \mathrm{T}$ & 3 \\
\hline PR14-GP2 & 19.2 & M & Nigeria & $1990 \mathrm{~s}$ & Minor surgery, CVD & $5-9$ & Salaried GP & $\mathrm{F} / \mathrm{T}$ & 2 \\
\hline PR14-GP3 & 6.4 & $\mathrm{~F}$ & London & $1980 \mathrm{~s}$ & Women's health & $20-24$ & $\begin{array}{l}\text { Salaried GP } \\
\text { clinical lead }\end{array}$ & $\mathrm{P} / \mathrm{T}$ & 1 \\
\hline
\end{tabular}

The participant identification code identified the practice $(P R 1=$ practice one) and the different types of participant: $G P=$ general practitioner; $N U=$ nurse prescriber.

${ }^{b}$ Actual dates of qualification are not given to preserve anonymity. ${ }^{c}$ Actual number of years in the profession are not given to preserve anonymity. ${ }^{d} A l l$ four interviews were conducted by a GP. CVD = cardiovascular disease. COPD = chronic obstructive pulmonary disease. ENT = ear, nose and throat. $F=$ female. $F / T=$ full-time. $M=$ male. $N / A=$

not applicable. $P / T=$ part-time.

their therapeutic training, drug knowledge and experience, knowledge of the patient, perception of risk, and physical and emotional health. A lot of GPs' therapeutic knowledge was felt to have been picked up on the job by talking among their hospital peers while in training. The importance of hands-on training experience with a range of chronic disease patients at varying stages of their illnesses was emphasised: 
Table 2. Summary of participants contributing to the six focus groups

\begin{tabular}{|c|c|c|c|c|c|c|}
\hline $\begin{array}{l}\text { Focus group } \\
\text { number }\end{array}$ & $\begin{array}{l}\text { Length of focus } \\
\text { group, minutes }\end{array}$ & $\begin{array}{c}\text { Participants in } \\
\text { each focus group, } n\end{array}$ & GPs, $n$ & Nurses, $n$ & Reception staff, $n$ & Other staff, $n^{\mathrm{a}}$ \\
\hline FG1 & 42 & 7 & 3 & 0 & 1 & 3 \\
\hline FG2 & 56 & 9 & 3 & 2 & 0 & 4 \\
\hline FG3 & 60 & 9 & 4 & 1 & 1 & 3 \\
\hline FG4 & 72 & 7 & 3 & 1 & 2 & 1 \\
\hline FG5 & 45 & 5 & 2 & 1 & 1 & 1 \\
\hline FG6 & 35 & 9 & 3 & 2 & 2 & 2 \\
\hline Total & N/A & 46 & 18 & 7 & 7 & 14 \\
\hline
\end{tabular}

"You never got any of the chronic conditions beyond a certain point so even if you diagnosed someone as diabetic you only had them on metformin and that would be it.' (PR3-GP2)

GPs tended to develop a repertoire of drugs that they were comfortable prescribing and exercised caution when using new, unusual, or unfamiliar drugs. One GP felt that time pressures made it difficult for her to calculate doses based on weight for paediatric patients and admitted just putting 'as directed' on her prescriptions. Some GPS admitted becoming 'slightly blasé' (PR1-GP1) about prescribing overtime, possibly running the risk of overlooking certain things.

GPs appeared to perceive and manage risk differently, with one GP admitting being much more 'laissez faire' about things than his colleagues:

And so there'll be some doctors, like $X$, who's very thorough and really spends] a lot of time on these things and there'll be some doctors, like me, at the other end probably who are much more laissez faire about this. Hopefully still safe but less worried about medication in general'. (PR4-GP1)

Perceptions of risk appeared to be influenced by whether the GP was aware of having made an error in the past and the severity of potential adverse drug effects. Tiredness and anxiety may also have affected the ability of some GPs to concentrate.

\section{The patient}

Patient characteristics and the complexity of the individual clinical case were found to have contributed to prescribing errors. GPs perceived some patients as difficult and demanding:

'She's the kind of patient that knows what she wants and she tells you what she wants.' (PR11-GP2)

'[Some patients] actively change their medication on a regular basis because they think know best.' (PR1-GP1)

[Some patients could do a] circuit of all the doctors for the same thing [in order] to get the answer that they want.' (PR7-GP1)

A tension was highlighted between the GP's responsibility to improve or maintain their patient's health and the patient's responsibilities for their own health. One GP admitted compromising with his patient in order for her to agree to have regular lithium monitoring done. The fact that she had been stable on lithium for quite a long time and had agreed to follow instructions if her results were abnormal, solicited just enough leniency from this GP to allow her to have blood tests extended to every 6 months (rather than every 3 months).

\section{The team}

Poor communication and nurses' 'quasiautonomous role' (PR3-GP1) in chronic disease management were considered to be two key conditions influencing the occurrence of prescribing errors. Several GPs' accounts highlighted the importance of feeling comfortable within the practice team and being able to share any anxieties or worries that they may have. Although it had become customary in general practice for GPs to sign prescriptions generated by nurses, one GP questioned the safety of this process:

'[l find it] a little bit uncomfortable because I'm not actually seeing the patient myself but it's the nature of general practice, it's the way it's happened for many years. That's not to say it's the right way but, you know, at 
the moment these particular girls [nurses] haven't, can't prescribe for themselves. (PR2-GP1)

The responsibility associated with signing these prescriptions appeared to weigh heavily on several GPs' minds, with some preferring the idea of independent nurse prescribers who signed their own prescriptions.

\section{The working environment}

GPs and practice staff reported regular periods of high workload and time pressures:

'If I'm running an hour late, (...) the first lady [seen in the surgery] didn't get much of a clinical entry or got a very badly typed one. (PR3-GP1)

'The critical use of time is for me the biggest single stress factor in general practice. The fact that there's so much to do in such a short space of time, that you are almost inevitably going to make some mistake. (PR2-GP2)

Two important conditions were felt to contribute to this inherently stressful working environment: the appointment system and patient demand. One GP recounted how they had an obligation to offer patients an appointment within a specified period of time, but questioned this necessity when patients often turn up with only routine issues.

The potential for GPs to be distracted and interrupted was felt to be enormously high:

'[Distractions] knock us out of our stride [and things] go wrong because you're not in that closed zone and giving it your entire attention. '(PR3-GP1)

Several doctors described how difficult it was when nurses put their head round the corner' (PR2-GP1) and ask them to sign prescriptions (as described above). It was felt that such interruptions could lead to errors if they did not take sufficient time to stop and look at what the nurse had prescribed. For others, their most pressing concern was how they may lose track of what they had been entering before they got interrupted:

You get interrupted in-between times, the minute somebody sees your door open they pounce, or sees a patient leave they pounce and you're filling in the notes and suddenly somebody's pounced, then that distracts you from completing the notes properly or completing the task properly because you don't write all the notes in with the patient. And then you're running late so you, I suppose cut corners would be a way of describing it, you try, and then that's when it goes wrong.' (PR3-GP1)

Some GPs also described how difficult it was to maintain concentration when the patient was 'sort of nattering in your ear' (PR7-GP1) or 'comes and presents you with a whole battery of symptomology' (PR3-GP1):

'This lady brings an awful lot to the table. And she persistently overruns her consultation. (..) And it's often the "while I'm here" scenario, "oh by the way" or you get so cluttered up in your 10 minute task with other things (...) all the time, she gives you that feeling "Oh God, she's back again!" and so what happens is you get distracted and you don't complete the task because you're just relieved and you're 20 minutes late, and you just quickly sort things out.' (PR3-GP1)

\section{The task}

This study concentrates on two main medication-related tasks in general practice: repeat prescribing and patient monitoring. Risks were presented in the ordering, processing, and signing stages of repeat prescribing. One practice stopped receiving requests on the phone because of the potential for medication errors. Concerns were also raised around patients ticking the wrong box on SystmOne IGP clinical system) when you have two drugs with similar names next to one another. One GP recalled how a few significant events had occurred in the processing stage, with multiple prescriptions getting mixed up or separated for the same patient. Another GP explained how sometimes short courses can become long ones when he is not giving the task his full attention:

Inattention creeps in (...) you give them, you know, 2 weeks, 3 weeks whatever of ibu [ibuprofen] or another NSAID [non steroidal anti-inflammatory drug], and then they come back (...) to the desk, "Can so-and-so have an extra repeat?" or "They've just run out of this", "Can they have that?", it goes on. That then somehow ends up in perpetuity because it can get put on repeat.' (PR3-GP1)

Patient monitoring was influenced by a number of conditions including the practice system and the patient, the communication between healthcare settings, and the prescriber. One GP admitted that their practice was slightly more on the ad hoc side', relying on the patient to turn up for monitoring. 
We could probably sit down here and think which drugs do we want to actively monitor and we could just run a search on them every month (...) And it wouldn't be a huge job but we've never got round to it. So we rely on patients.' (FG2-GP2)

Patients on warfarin were felt to be especially hard to keep track of, with one GP explaining how the system really should be flagged up as a whole area [of] risk' (FG4-GP2).

'You can be issuing warfarin and have no idea what the patient's INR is and no idea whether they're turning up anywhere, and we're not automatically getting results through and advice that the clinics are giving: (FG4-GP2)

The role of the prescriber within the practice (locum or partner) was also felt to impact on patient monitoring, with locums in particular perceived as unwilling to take the necessary responsibility:

'There's a real risk that patients get lost to follow-up if their regular doctor isn't here all the time, like I'm not (...) there's a range of social services [issues for some of them] that (...) can be a lot of work and I dare say sometimes the GP in question says, "Crikey, stay well clear out of this one" sort of thing.' (PR6-GP2).

\section{The computer system}

Computer-related issues associated with selecting the wrong item from an electronic pick-list and unnecessary and/ or inappropriate alerts were highlighted as possible error producing conditions:

If you have too many warnings from the computer then that makes you tend to override them, you become a bit more cavalier and that's a danger.' (PR6-NU1)

Certain drugs, like insulin, were considered to be particularly difficult to pick from electronic lists:

'You've got to find the right word to start with [when picking insulin] or you don't get the right pick list.' (FG4 - Nurse 1).

The speed with which the computer operated may have also contributed to these picking errors:

'Our problem here is our computers are rubbish. They work really, really slowly (...) it takes a long time to come through so we scroll down an option, a pick list, it can pick the wrong thing which is very frustrating. (PR3-GP2)

'[l'm] surprised how many times it says 3 out of 3 [strong alert] and yet the doctors don't actually look at it.'(PR6-GP2).

\section{The primary-secondary care interface}

Problems with the timeliness, legibility, content, and layout of secondary care correspondence were all felt to increase the risk of prescribing errors. Patients often visited their GPs before this correspondence was received, which resulted in them trying to piece together what changes in patient management had been made with little or no information. The ambiguous wording of hospital letters was also highlighted, with one GP explaining how, on the top of the letter, it stated that there was no change to medication, yet, within the text of the letter, the hospital clinician was 'sort of suggesting' that a lower dose of risperidone should be prescribed. Although several GPs recognised the need to update patients' computer records promptly with the information lonce received), they also acknowledged how some may 'fall through the net' (FG4-GP2).

\section{DISCUSSION}

\section{Summary}

The study identified a multitude of errorproducing conditions classified into seven high-level categories (the prescriber, the patient, the team, the work environment, the task, the computer system, and the primarysecondary care interface) that contributed to prescribing and monitoring errors. Categories equivalent to those in Reason's model were identified, ${ }^{14}$ with an additional two (the computer system and the primarysecondary care interface) considered relevant for the English general practice setting.

\section{Strengths and the limitations}

The sampling strategy allowed the study to cover a range of different locations linnercity, urban, suburban and rural) and practices (GP training and dispensing). It is possible, however, that the recruited practices had relatively high levels of interest in prescribing and a greater openness to external scrutiny of potential prescribing errors. All interviewees spoke openly (and often candidly) about their experiences and the difficulties they faced. It is noted that the study practices had a higher than average deprivation score, ${ }^{8}$ which may have affected the generalisability of the findings. Finally, it is recognised that these data represent the accounts of the healthcare professionals interviewed, and may not necessarily accord with their behaviour. 


\section{Box 2. Summary of key recommendations}

GP training

- Additional educational support for newly qualified GPs to help them make the transition to providing ongoing medicines management for patients with complex long-term conditions.

\section{Continuing professional development for GPs}

- Development of strategies to support GPs in dealing appropriately with high-risk prescribing scenarios (balancing risks, benefits, patient requests, and the need to avoid error).

Clinical governance

- Conducting significant event audits.

- Reporting adverse prescribing events (and near misses) through the National Reporting and Learning System.

\section{Effective use of clinical computer systems}

- The training of GPs and practice staff so that they are able to make best use of prescribing safety features.

- More accurate and appropriate alerts to hazardous prescribing and to the need for blood test monitoring for certain drugs.

\section{Funding}

This work was supported by a grant from the General Medical Council. The views expressed in this publication are those of the authors and not necessarily those of the GMC or RCGP. The Centre for Medication Safety and Service Quality (CMSSQ) is affiliated with the Centre for Patient Safety and Service Quality (CPSSQ) at Imperial College Healthcare NHS Trust, which is funded by the National Institute of Health Research.

\section{Ethical approval}

Research ethics committee approval was obtained from Nottingham Research Ethics Committee 1 (Reference 10/H0403/29; 27 April 2010). NHS Research and Development approval was obtained from participating PCTs. The ethics committee agreed that patients did not have to give informed consent since their records were accessed only by pharmacists employed by the relevant PCT. No personal identifiable data were recorded.

\section{Provenance}

Freely submitted; externally peer reviewed.

\section{Competing interests}

The authors have declared no competing interests.

\section{Acknowledgements}

We thank all the general practices and participants who kindly gave their time. We also thank those who assisted with the recruitment of practices and the pharmacists who collected these data (Tess Dawoud, Gillian Gookey, Roshan Jayaseelan, Uzma Rashid). We are very grateful to our research administrator, Clare Randall, who checked the accuracy of the transcribed interviews.

\section{Discuss this article}

Contribute and read comments about this article on the Discussion Forum: http://www.rcgp.org.uk/bjgp-discuss

\section{Improving safety systems}

- General practices review the procedures they have in place for minimising interruptions to clinical staff, medication monitoring, and communication at interfaces in health care, to help ensure that these are as safe as possible in the context of high workload and multiple competing demands on staff.

\section{Comparison with existing literature}

Other studies in the hospital setting have reported similar error-producing conditions, such as a lack of training or experience. ${ }^{4-6}$ Some GPs struggled with the management of patients with complex, long-term conditions in this study, having only limited exposure to the varying stages of complex illnesses in training; this need should be addressed. A second important finding related to GPS perception of risk. Grol suggested that different cultures and forms of medical education may lead to differences in GPs attitudes to risk-taking between countries. ${ }^{16}$ Some GPs also acknowledged becoming slightly blasé about the treatment of patients who they had known for a long time. There may be benefits to using an independent health professional (such as a sessional practice pharmacistl to review these patients' repeat medications at appropriate intervals. ${ }^{17}$ Some patients were perceived as difficult and demanding; it is possible that they intentionally and consciously express themselves in a particular way to evoke a specific response from their GP. ${ }^{18,19}$ While patients' choices are important, ${ }^{20}$ some GPs may need help developing strategies to resist patient pressure to prescribe where the risks of harm are particularly high. Communication within and between practice colleagues and healthcare settings also appeared to influence the occurrence of prescribing errors. ${ }^{21}$ Interruptions went hand-in-hand with the process of signing nurse prescriptions in some practices, thus reinforcing the need for nurses to issue prescriptions based on their own clinical assessment and judgement as non-medical prescribers, in line with current

\section{UK legislation. ${ }^{22}$}

High workload and time pressures were also perceived to contribute to errors. The importance of time as a key component of the social organisation of health has previously been examined. ${ }^{23}$ GP workload levels need to be reviewed and adjusted to allow sufficient time for safe prescribing and medicines management. One option may be to increase the size of the GP workforce, while another may be to train more nonmedical prescribers, particularly sessional practice pharmacists, to deal with patients with complex medication regimes. ${ }^{24}$ The computer-related issues uncovered in this study have previously been highlighted in the literature. ${ }^{25-27}$ General practices need to make the best use of the existing features of their clinical computer systems. A number of recommendations arose from this mixedmethods study; ${ }^{9}$ these are summarised in Box 2. Further research has also been funded to look at specific tools to assess different aspects of patient safety and how these errors can be reduced. ${ }^{28}$

\section{Implications for research and practice}

This study highlighted the complex underlying causes of prescribing and monitoring errors in general practices. Several of these are amenable to intervention, including improved training and safer systems for medication review and monitoring, while others are likely to be more difficult to address, such as workload and time pressures. Nevertheless, by tackling the range of issues identified in this study, it is possible that substantial improvements could be made to the safety of prescribing in general practices. 


\section{REFERENCES}

1. The NHS Information Centre for Health and Social Care. Prescriptions dispensed in the community: England, statistics for 2000 to 2010. http:// www.ic.nhs.uk/statistics-and-data-collections/primary-care/prescriptions/ prescriptions-dispensed-in-the-community-england-statistics-for-2000-to-2010 laccessed 15 Aug 2013).

2. Shah $\mathrm{SNH}$, Aslam M, Avery AJ. A survey of prescription errors in general practice. Pharm J 2001; 267: 860-862.

3. Howard R, Avery A, Bissell P. Causes of preventable drug-related hospital admissions: a qualitative study. Qual Saf Health Care 2008; 17(2): 109-116.

4. Dornan T, Ashcroft D, Heathfield H, et al. An in depth investigation into causes of prescribing errors by foundation trainees in relation to their medical education - EQUIP Study. London: General Medical Council, 2009.

5. Dean B, Schachter M, Vincent C, et al. Causes of prescribing errors in hospital inpatients: a prospective study. Lancet 2002; 359(9315): 1373-1378.

6. Tully MP, Ashcroft DM, Dornan T, et al. The causes of and factors associated with prescribing errors in hospital inpatients: a systematic review. Drug Safety 2009; 32(10): 819-836.

7. National Patient Safety Agency. Safety in doses: improving the use of medicines in the NHS. 3. Learning from national reporting 2007. London: National Patient Safety Agency, 2009. http://www.nrls.npsa.nhs.uk/EasySiteWeb/getresource. axd?Asset ID=61626 laccessed 15 Aug 2013).

8. Avery AJ, Ghaleb M, Barber N, et al. The prevalence and nature of prescribing and monitoring errors in English general practice: a retrospective case note review. Br J Gen Pract 2013; DOI: 10.3399/bjgp13X670679.

9. Avery AJ, Barber N, Ghaleb M, et al. Investigating the prevalence and causes of prescribing errors in general practice: The PRACt/Ce Study. A report for the General Medical Council. London: GMC, 2012. http://uww.gmc-uk.org/ Investigating_the_prevalence_and_causes_of_prescribing_errors_in_general practice__The_PRACtICe_study_Reoprt_May_2012_48605085.pdf laccessed 15 Aug 2013).

10. Dean B, Barber N, Schachter M. What is a prescribing error? Qual Health Care 2000; 9(4): 232-237.

11. Lewis PJ, Dornan T, Taylor D, et al. Prevalence, incidence and nature of prescribing errors in hospital inpatients: a systematic review. Drug Safety 2009; 32(5): 379-389.

12. Alldred DP, Standage C, Zermansky AG, et al. Development and validation of criteria to identify medication-monitoring errors in care home residents. Int $J$ Pharm Pract 2008; 16: 317-323.

13. Pope C, Ziebland S, Mays N. Analysing qualitative data: qualitative research in health care. BMJ 2000; 320(7227): 114-116

14. Reason J. Human error. Cambridge: Cambridge University Press, 1990.

15. Strauss A, Corbin J. Basics of qualitative research, grounded theory procedures. London: Sage, 1990.

16. Grol R, Whitfield M, De Maeseneer J, Mokkink H. Attitudes to risk taking in medical decision making among British, Dutch and Belgian general practitioners. Br J Gen Pract 1990; 40(333): 134-136.

17. Avery AJ, Rodgers S, Cantrill JA, et al. A pharmacist-led information technology intervention for medication errors (PINCER): a multicentre, cluster randomised, controlled trial and cost-effectiveness analysis. Lancet 2012; 379(9823): 13101319.

18. Goffman E. The presentation of self in everyday life. London: Penguin, 1990.

19. Bradley CP. Uncomfortable prescribing decisions: a critical incident study. BMJ 1992; 304(6822): 294-296.

20. Cribb A, Barber N. Prescribers, patients and policy: the limits of technique. Health Care Analysis 1997; 5(4): 292-298.

21. Care Quality Commission. Managing patients' medicines after discharge from hospital. London: Care Quality Commission, 2009. http://archive.cqc.org.uk laccessed 15 Aug 2013).

22. The Department of Health. The non-medical prescribing programme. http://webarchive.nationalarchives.gov.uk/+/uww.dh.gov.uk/en/ Healthcare/Medicinespharmacyandindustry/Prescriptions/TheNonMedicalPrescribingProgramme/DH_099234 laccessed 15 Aug 2013).

23. Frankenberg R. Your time or mine: temporal contradictions of biomedical practice. In: Frankenberg R (ed.). Time, health and medicine. London: Sage, 1992.

24. Magnus D, Rodgers S, Avery AJ. GPs' views on computerized drug interaction alerts: questionnaire survey. J Clin Pharm Ther 2002; 27(5): 377-382.

25. Avery AJ, Savelyich B, Sheikh A, et al. Improving general practice computer systems for patient safety: qualitative study of key stakeholders. Qual Saf Health Care 2007; 16(1): 28-33.

26. Nanji KC, Rothschild JM, Salzberg C, et al. Errors associated with outpatient computerized prescribing systems. J Am Med Inform Assoc 2011; 18(6): 767 773.

27. Avery AJ, Dex GM, Mulvaney C, et al. Development of prescribing-safety indicators for GPs using the RAND Appropriateness Method. Br J Gen Pract 2011; DOI: 10.3399/bjgp11X588501.

28. University of Oxford. NSPCR Patient Safety Toolkit. http://www.phc.ox.ac.uk/ research/hsprg/research-projects/toolkit laccessed 16 Sep 2013). 